\title{
Neuroimaging Findings in Racemose Neurocysticercosis: Case Description and Literature Review
}

\begin{abstract}
Nikoletta Kollia, MD ${ }^{*}$, (D); Aikaterini Theodorou, MD ${ }^{*}$ (D); Paschalis Zervas, MD* (D); Lina Palaiodimou, MD* (D); Matilda Papathanasiou, $\mathrm{MD}, \mathrm{PhD}^{\dagger}$ (D); Panagiotis Toulas, $\mathrm{MD}^{\dagger}$ (D); Maria Theodorakopoulou, $\mathrm{MD}^{\ddagger}$ (D); Georgios Dimopoulos, $\mathrm{MD}^{\ddagger}$ (D); Drosos Karageorgopoulos, $\mathrm{MD}^{\mathbb{1}}$ (D); Elisabeth Andreadou, MD" (D); Anastasios Bonakis, MD, PhD* (D); Konstantinos Voumvourakis, MD, PhD* (i); Georgios Tsivgoulis, MD, PhD * (I)

Second Department of Neurology, "Attikon" University Hospital, National and Kapodistrian University of Athens, School of Medicine", Athens; Second Department of Radiology, "Attikon" University Hospital, National and Kapodistrian University of Athens, School of Medicine ${ }^{\dagger}$, Athens; Second Department of Critical Care Medicine, "Attikon" University Hospital, National and Kapodistrian University of Athens, School of Medicine ${ }^{\ddagger}$, Athens; 4th Department of Internal Medicine, Attikon University General Hospital, National and Kapodistrian University of Athens, School of Medicine ${ }^{\natural}$, Athens; First Department of Neurology, Aeginition Hospital, National and Kapodistrian University of Athens, School of Medicine", Athens, Greece; Department of Neurology, The University of Tennessee Health Science Center ", Memphis, TN, USA
\end{abstract}

Neurocysticercosis (NCC), the most common central nervous system (CNS) parasitic infection among the immunocompetent population can imitate every clinical feature of brain-diseases accurately, drawing attention away from the real culprit and delaying the proper treatment. There are two types of NCC, the parenchymal and the extraparenchymal form. The extraparenchymal NCC include the ventricular cysticercosis, the subarachnoid cysts including giant cysts or racemose cysticercosis with chronic meningitis, the spinal (intra- or extramedullary) cysticercosis and the ophthalmic cysticercosis. It is estimated that about $30 \%$ of epilepsy cases in endemic countries are due to NCC and especially the racemose NCC is more aggressive and associated with higher mortality rates. There is a significant heterogeneity in clinical phenotypes, regarding the racemose NCC, which depends on the parasite load and evolutionary stage in association with its location in CNS and the host's immune response. Crucial for the management of the racemose NCC is the early recognition of the symptoms and the swift initiation of antiparasitic therapy with anti-inflammatory agents in combination with the shunt-insertion in cases of obstructive hydrocephalus. In view of the former considerations we conducted a narrative literature review on racemose NCC and described the diagnostic challenges of a relevant case that we had evaluated in our Department of Neurology.

J Neurosonol Neuroimag 2021;13(2):37-46

Key Words: Racemose neurocysticercosis; Parasitic diseases; Dementia; Epilepsy
Received: March 23, 2021

Revised: June 29, 2021

Accepted: July 21, 2021

Correspondence:

Georgios Tsivgoulis, MD, PhD

Second Department of Neurology, "Attikon" University Hospital, National and Kapodistrian University of Athens, School of Medicine, Rimini 1, Chaidari, Athens 12462, Greece

Tel: $+30-6937178635$

Fax: $+30-2105832471$

E-mail: tsivgoulisgiorg@ yahoo.gr

${ }^{1}$ The two authors contributed equally to the work.

\section{INTRODUCTION}

Neurocysticercosis (NCC) is the most common subacute/chronic pleomorphic parasitic infection of the central nervous system (CNS) caused by the larval form of the pork tapeworm Taenia Solium. ${ }^{1}$ The most frequent involved sites are the central nervous system, the eye and the muscle but T. Solium can affect any organ.
Although it is highly endemic in rural areas of the developing world, on behalf of poor sanitary conditions, is still under-diagnosed. The clinical manifestations depend on the parasite load and the host's immune response regarding their location in CNS and their evolutionary stage. ${ }^{2}$ There are two types of NCC, the parenchymal and the extraparenchymal form. The extraparenchymal racemose NCC has the worst prognosis 
among all forms of NCC with mortality ranging between $30 \%$ and $80 \%$.

However, the early recognition of symptoms such as rapidly progressive dementia, late-onset seizures and psychiatric manifestations would allow a prompt begin of antiparasitic therapy, which could be life-saving in this uncommon but devastating central nervous system disorder.

\section{CASE PRESENTATION}

A 65-year-old male, shepherd from Albania presented in our Department of Neurology with continuously deteriorating cognitive impairment and gait imbalance with frequent falls during the past 6 months. He had a long history of headaches and seizures by the age of 25 and two psychiatric hospitalizations (8 years ago) in Albania because of aggressive behavior.

Neurological examination revealed disorientation and apathy. He scored 8/30 on the Mini-mental State Examination (MMSE) with substantial impairment of the cognitive domains including executive function, verbal fluency, working and episodic verbal memory, the visuospatial orientation and calculation.

Furthermore, he presented with gait imbalance, stiffness of upper extremities and bilateral extensor plantar reflexes. Our examination on the admission revealed affected body balance even in the sitting position. He could walk with his feet wide apart and with the assistance of two persons. Electroencephalography was highly indicative of diffuse frontal cerebral dysfunction and prone to focal seizures.

The cerebrospinal fluid (CSF) analysis indicated yellowish colored fluid with mild lympocytosis $(=15$ cells), hypoglycorrhachia (glucose in CSF/glucose in serum $=10 / 100 \mathrm{mg} / \mathrm{dL}$ ) and mild increase in protein concentration $(64 \mathrm{mg} / \mathrm{dL})$. The patient was extensively tested for tuberculosis. Quantiferon test, two consecutive CSF-cultures and CSF-polymerase chain reaction (PCR) analysis for mycobacterium of tuberculosis were all negative, excluding this differential diagnosis. The bacteria culture tests and PCR analysis of CSF for different viruses (Cytomegalovirus, Epstein-Barr Virus, Herpes simplex Virus-1, Herpes simplex Virus-2, Varizella-Zoster Virus, Enteroviruses) were negative, whereas the oligoclonal bands examination showed immunoglobin (IgGs) intrathecal synthesis in CSF and increased IgG INDEX (=2.70 with normal range $<0.65)$. The cytological analysis of CSF did not reveal any malignancy but was positive for inflammation with high number of CD138(+) plasmatocytes while the immunophenotype and flow cytometer of the same sample presented T-polyclonal cells.

Results of serological tests including human immunodeficiency virus antibody/antigen, Venereal Disease Research Laboratory (VDRL), Bartonella/Listeria type I and $4 \mathrm{~b} /$ Brucella and Cryptococcus antibodies were negative. Rheumatologic workup including anticardiolipin/b2-glycoprotein antibodies, lupus anticoagulant, antinuclear antibodies, antineutrophil cytoplasmic antibody, $\mathrm{C}_{3}$ and $\mathrm{C}_{4}$ complement levels and serum angiotensin converting enzyme revealed unremarkable results. Test for NCC on antibody-enzyme linked immunosorbent assay (Ag-ELISA) in both CSF and Serum was negative.

Brain magnetic resonance imaging (MRI) depicted obstructive hydrocephalus and multiple subarachnoid cysts (left sylvian fissure and prepontine cistern) highly suggestive of racemose NCC. Ependymitis, ventriculitis, perivascular gadolinium enhancement and parenchymal granular stage cysts were also illustrated. There were no signs of systemic cysticercosis ascertained by the diagnostic workflow (Figs. 1, 2).

Enzyme-linked immunotransfer blot (EITB) assay, which was positive both in serum and CSF ascertained, in combination with the clinical manifestations and the radiological findings ascertained the diagnosis of subarachnoid racemose NCC.

A shunt was inserted intraventricularly. However, brain biopsy results were inconclusive due to friability of brain tissue as a result of the underlying inflammation and technical limitations related to the biopsy sample.

When treatment with albendazole, praziquantel and corticosteroids was administered at a late stage, the extensive parenchymal damage due to inflammation and dilatation of ventricular system was adverse prognostic factor that was associated with an unfavorable clinical outcome. The patient failed to respond to antiparasitic treatment and died 3 months following admission to our Department of Neurology because of neurological 
deterioration.

\section{PARASITOLOGY-PATHOGENESIS}

Taenia solium is a two-host zoonotic cestode. The human can act as both intermediate and definitive host and is the only known final host for T. Solium tapeworms in nature. ${ }^{3}$ In areas with poor sanitation pigs ingest feces containing ova, which develop into cysticerci in their tissue. Humans become infected after ingestion of infected pigs with cysticerci or larvae in tissue. ${ }^{4}$ Other studies conclude as well to person-to-person spread from cysticercosis, since they have shown a significant human cysticercosis seroprevalence gradient surrounding tapeworm carriers; tapeworm carriers can spread the eggs to other through fecal-oral contamination. ${ }^{5}$
In most cases NCC produces symptoms many years after the initial invasion of the central nervous system of the parasite. The cysts may be located in the brain, subcutaneous tissue, muscles, eyes and rarely in the spinal cord and other tissues.

The parasite commonly affects the central nervous system, causing NCC. There are two types of NCC: the parenchymal, which is classified into non-cystic, vesicular, colloidal vesicular, granular nodular and calcified nodular and the extraparenchymal. ${ }^{6}$ The extraparenchymal form include the ventricular cysticercosis, the subarachnoid cysts including giant cysts or racemose cysticercosis with chronic meningitis, the hydrocephalus with no visible cysts, the spinal (intra- or extramedullary) cysticercosis and the ophthalmic cysticercosis. ${ }^{3,4}$

In parenchymal form mortality is limited to epilepsy-related deaths, unless there is a high burden of cysts.
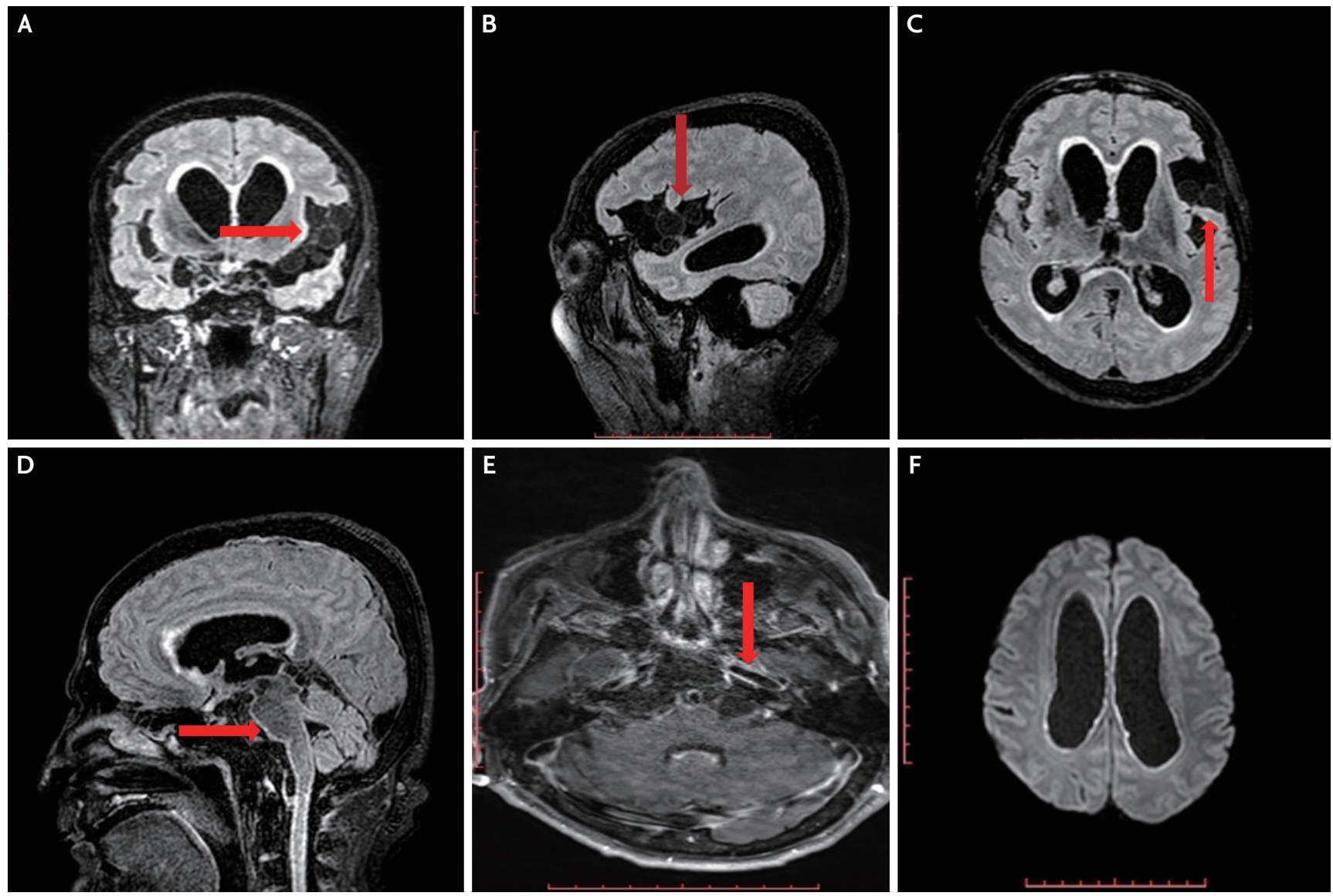

FIG. 1. (A-D) Fluid-attenuated inversion recovery sequences showing multiple cysts in the subarachnoid/cisternal space: prepontine cistern and left sylvian fissure (arrow). (E) There was evidence of perivascular gadolinium enhancement (T1 post contrast) suggesting inflammation in the subarachnoid space (arrow) and (F) restricted diffusion of ependyma (diffusion-weighted imaging) indicating the presence of ventriculits causing hydrocephalus. 
On the other head, extraparenchymal form is related with high mortality rates, mainly due to intracranial hypertension, which in the most of the cases requires aggressive management.

\section{EPIDEMIOLOGY}

Endemic regions for NCC are the most Latin American countries, sub-Saharan Africa and large regions of Asia, including the Indian subcontinent, most of Southeast Asia, and China; and the number of endemic countries continues nowadays to increase. ${ }^{5,7}$ Imported NCC due to immigration is being increasingly recognized in Europe, United States and in Canada, reflecting the high endemicity of the infection in their countries of

\section{origin. ${ }^{8}$}

Until 2010 NCC was referred to as "neglected" disease. However, Coyle et al. ${ }^{8}$ in 2012 implies correctly, that NCC may be neglected but not forgotten. An estimation from World Health Organization suggests about 2.56-8.30 million people with NCC globally. ${ }^{9}$ It is estimated, that about $30 \%$ of epilepsy cases in endemic countries are due to NCC and in high risk communities it can be associated with as many as 70\% of epilepsy cases. $^{10}$

Racemose NCC is clinically more aggressive and is considered as the malignant form of NCC. ${ }^{11}$ In the literature it is reported in $15-54 \%$ of the patients and is associated with a high mortality rate when it is complicated with hydrocephalus secondary to cysticercal meningitis. ${ }^{12}$
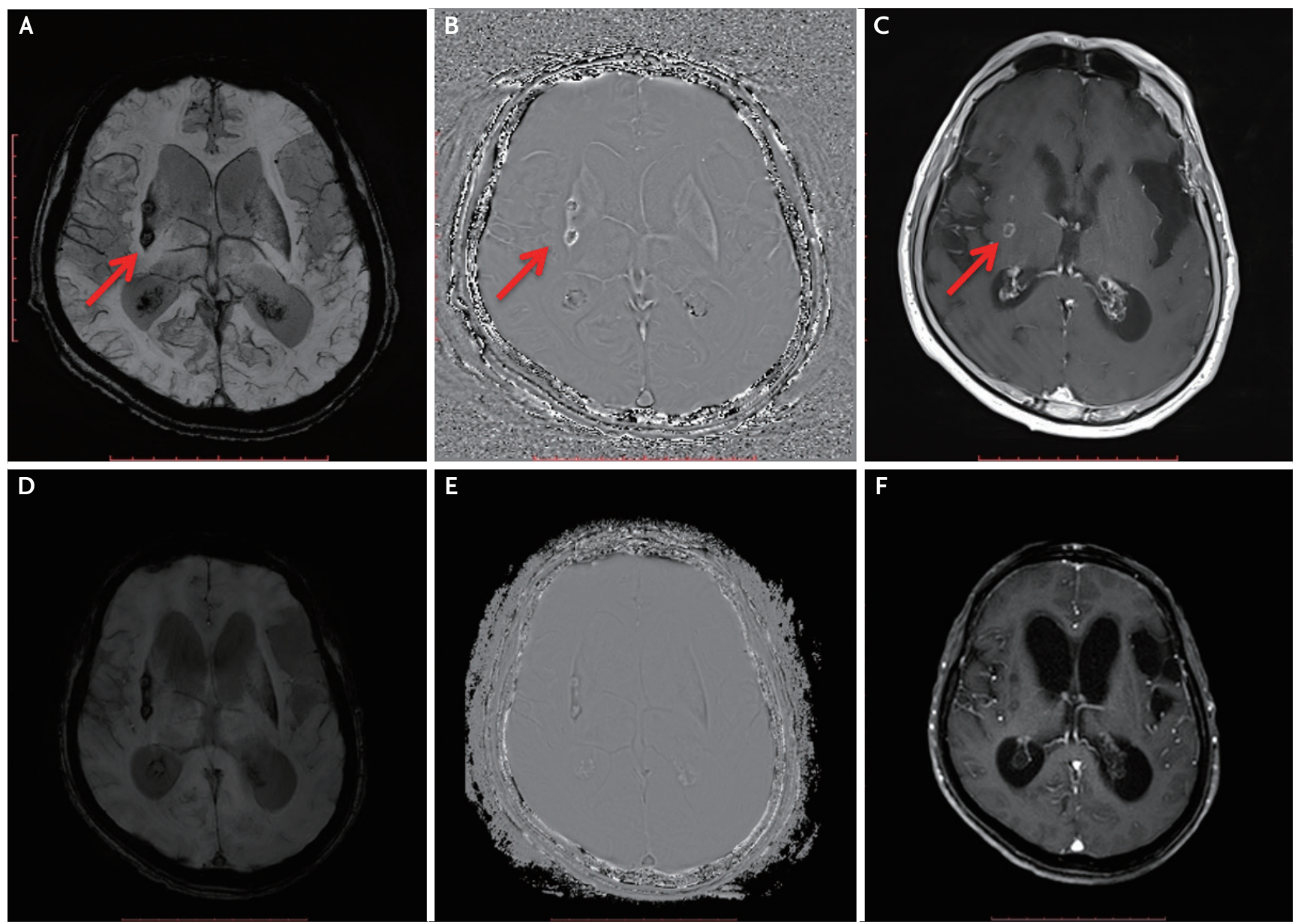

FIG. 2. (A-C) A granular cyst in right basal ganglia with hemosidirin deposition (arrow) on susceptibility weighted imaging (SWI) ([A] SWI, [B] phase $S W I$ ) and (C) gadolinium ring enhancement (T1 post contrast) transformed into a calcified lesion ([D] SWI, [E] phase SWI) without (F) gadolinium enhancement ( $T_{1}$ post contrast) 3 months later. 


\section{CLINICAL PRESENTATION AND RADIOLOGICAL FEATURES}

Racemose NCC refers to cysticerci who are lodged either in the subarachnoid space of the basal cisterns, Sylvian fissure, spinal medulla or in the ventricular system. The appearance of parasites in those locations, especially in the subarachnoid space appears like a cluster of grapes, and thus were termed racemose cysts., ${ }^{411}$

Racemose NCC is thought to be due to a different form of $\mathrm{T}$. solium, which could be either an aberrant cysticercus of $\mathrm{T}$. solium or a coenurus cerebralis, which is an intermediary stage of the adult tapeworm, T. multiceps or T. serialis.

This form is much less frequent and studied than the parenchymal one and a significant heterogeneity in clinical phenotypes occurs regarding the obstruction of CSF flow, the mass effect phenomena and the inflammation spread into arachnoid/ependymal tissues or blood vessels causing arachnoiditis/ependymitis or vasculitis respectively (Table 1). The latency period between infection and symptoms appearance is long and usually this clinical entity is overlooked for years or even decades. ${ }^{13}$

Typical clinical presentation of the racemose NCC is the adult-onset seizure in combination with a long history of headache and other neurological symptoms such as vomiting and fatigue. Hydrocephalus is in the most cases obstructive, due to either meningitis and adhesions (meningeal form), that result in CSF obstruction or due to ependymitis caused by the death of larva in the ventricular/subarachnoid form which result in ventricular outlet obstruction. ${ }^{11-13}$

The intraventricular form of NCC is associated with the highest mortality and morbidity with the 4 th ventricle being the most common affected site (53\%) followed by the third (27\%). ${ }^{13}$ Yerneni et al. ${ }^{14}$ published in 2020 a typical case report of a 34-year-old female presenting with late-onset of seizure and a long history of headache, due to lobulated cystic mass within the 4 th ventricle resulting in obstructive hydrocephalus. Free-floating cysts in ventricles, especially in the 4 th ventricle can cause Brun's syndrome, characterized by intermittent foraminal obstruction induced by rotatory movements of head/neck and causing episodic recurrent headaches, vertigo, ataxia, drop attacks, loss of consciousness with rapid recovery. ${ }^{15}$

Machado-Porto et al. ${ }^{16}$ described an uncommon presentation of reversible dementia due to underlying hydrocephalus caused by NCC in its racemose form. Dementia is a rare complication and sometimes the presenting feature in racemose NCC. The mechanisms proposed for dementia are raised intracranial pressure, location of the parasite and the host's immune response.

Racemose NCC can also present with a mass effect; Kumar et al. ${ }^{17}$ reported an interesting case of a 22-yearold male, presenting with headache and seizures since 4 years, due to a giant multi-loculated cystic mass in left choroid fissure causing mass effect on the hippocampus and compression on the left lateral ventricle.

Other sensational clinical and radiological manifestations of racemose, described in the literature is the trigeminal neuralgia due to multiple cysts in the posterior fossa cisterns, mainly in the cerebellopontine angles. ${ }^{18}$ Grape-like clusters in the sellar and suprasellar regions is also reported to cause characteristic syndrome with amenorrhoea, recurrent vomiting, headache and increased fatigue. ${ }^{19}$ Chronic papilledema with bilateral optic atrophy was also reported by Matalia et al. ${ }^{20}$ and attributed to multiloculated cysts in the basal cisterns, right sylvian, and anterior interhemispheric fissure with moderate obstructive hydrocephalus.

NCC has been shown to consist a risk factor, independent from other risk factors, for stroke in young and middle-aged patients. Subarachnoid NCC is mainly due to the subarachnoid cysts, while the underlying arteritis can cause occlusion of cerebral arteries leading to cerebral infarctions. The most commonly affected cerebral vessels are the middle and posterior arteries and the incidence of cerebrovascular diseases in patients with racemose NCC is between $4 \%$ and $12 \% .{ }^{21-24}$

Spinal NCC is a rare manifestation and constitutes about $1-5 \%$ of all cases of NCC. The most frequent presentation is the subarachnoid (leptomeningeal) extramedullary form and less common is the intramedullary form. ${ }^{4,13}$ The spinal NCC is very difficult to treat, especially when it is associated with arachnoiditis and has a poor prognosis. ${ }^{25}$ Few cases with spinal racemose NCC are reported in the literature, one of the these was published by Yacoub et al. ${ }^{26}$ in 2017. 
TABLE 1. Main clinical and radiological characteristics of racemose neurocysticercosisStudy

\begin{tabular}{|c|c|c|c|c|}
\hline & Main clinical manifestation & Main radiological feature & Country & Patient characteristics \\
\hline Yerneni et al. ${ }^{14}$ (2020) & $\begin{array}{l}\text { Adult onset seizures \& } \\
\text { 1-year history of bilateral } \\
\text { headaches with vertigo } \\
\text { and intermittent nausea }\end{array}$ & $\begin{array}{l}\text { Obstructive hydrocephalus \& lob- } \\
\text { ulated cystic mass within the } 4 \text { th } \\
\text { ventricle }\end{array}$ & $\begin{array}{l}\text { United States } \\
\text { (born and raised } \\
\text { in Mexico until } \\
\text { the age of } 8 \text { ) }\end{array}$ & $\begin{array}{c}\text { Female } \\
\text { (36-year-old) }\end{array}$ \\
\hline $\begin{array}{l}\text { Diehl Rodriquez et al. }{ }^{15} \\
(2012)\end{array}$ & $\begin{array}{l}\text { Brun's Syndrom: new on- } \\
\text { set of tonic-clonic seizure } \\
\& \text { headaches with pro- } \\
\text { gressive bilateral visual } \\
\text { and hearing loss }\end{array}$ & $\begin{array}{l}\text { Arachnoiditis and cystic lesions } \\
\text { beside the pontine cistern, the } \\
\text { interpeduncular cistern, and the } \\
\text { bulbo-cerebellar cistern with hy- } \\
\text { drocephalus }\end{array}$ & $\begin{array}{l}\text { Urban Region of } \\
\text { South Brazil }\end{array}$ & Female (43-year-old) \\
\hline $\begin{array}{l}\text { Machado-Porto et al. }{ }^{16} \\
(2015)\end{array}$ & $\begin{array}{l}\text { Reversible dementia \& gait } \\
\text { disorder with urinary in- } \\
\text { continence }\end{array}$ & $\begin{array}{l}\text { Moderate hydrocephalus \& as a } \\
\text { "bunch of grapes", multiple cysts } \\
\text { in the right Sylvian fissure }\end{array}$ & Sao Paulo-Brazil & Female (63-year-old) \\
\hline Kumar et al. ${ }^{17}(2013)$ & $\begin{array}{l}\text { Seizures and headache } \\
\text { since } 4 \text { years }\end{array}$ & $\begin{array}{l}\text { Giant multi-loculated cystic mass in } \\
\text { left choroid fissure causing mass } \\
\text { effect on the hippocampus and } \\
\text { compression on the left lateral } \\
\text { ventricle }\end{array}$ & India & Male (22-year-old) \\
\hline $\begin{array}{l}\text { Hamamoto Filho et al. }{ }^{18} \\
(2016)\end{array}$ & $\begin{array}{l}\text { Painful trigeminal neurap- } \\
\text { athy }\end{array}$ & $\begin{array}{l}\text { Multiple cysts in the posterior fossa } \\
\text { cisterns, mainly in the cerebello- } \\
\text { pontine angles }\end{array}$ & Brazil & Male (64-year-old) \\
\hline Dutta et al. ${ }^{19}(2013)$ & $\begin{array}{l}\text { Amenorrhoea, recurrent } \\
\text { vomiting, headache and } \\
\text { increased fatigue }\end{array}$ & $\begin{array}{l}\text { Grape-like clusters in the sellar } \\
\text { and suprasellar regions \& also } \\
\text { shown: some single cysts in the } \\
\text { cerebellum/brainstem and in the } \\
\text { grey-white matter junction of the } \\
\text { cerebral cortex }\end{array}$ & Calcutta, India & Female (29-year-old) \\
\hline Matalia et al. ${ }^{20}(2014)$ & $\begin{array}{l}\text { Chronic papilledema with } \\
\text { bilateral optic atrophy }\end{array}$ & $\begin{array}{l}\text { Multiloculated cysts in the basal } \\
\text { cisterns, right sylvian, and ante- } \\
\text { rior interhemispheric fissure with } \\
\text { moderate obstructive hydroceph- } \\
\text { alus }\end{array}$ & India & Male (22-year-old) \\
\hline Levy et al. ${ }^{21}$ (1995) & $\begin{array}{l}\text { Right hemiparesis and } \\
\text { nonfluent aphasia }\end{array}$ & $\begin{array}{l}\text { Subacute infarcts in the left MCA } \\
\text { distribution, due to occlusion of } \\
\text { the left ICA at the level of the an- } \\
\text { terior choroidal artery with bilat- } \\
\text { eral occlusion of the A2 segments } \\
\text { of the ACAs. Hydrocephalus. }\end{array}$ & $\begin{array}{l}\text { Guadalajara,- } \\
\text { Mexico }\end{array}$ & Female (51-year-old) \\
\hline Yacoub et al. ${ }^{26}$ (2017) & $\begin{array}{l}\text { Bilateral arm numbness } \\
\text { and weakness \& gait in- } \\
\text { stability }\end{array}$ & $\begin{array}{l}\text { Multiseptated cystic lesions in the } \\
\text { upper cervical spinal canal \& non- } \\
\text { enhancing intradural extramedul- } \\
\text { lary cystic lesions in the thoracic } \\
\text { spine }\end{array}$ & Mexico & Male (49-year-old) \\
\hline Present study & $\begin{array}{l}\text { Rapidly progressive de- } \\
\text { mentia and gait instabili- } \\
\text { ty }\end{array}$ & $\begin{array}{l}\text { Obstructive hydrocephalus \& } \\
\text { multiple subarachnoid cysts \& } \\
\text { ependymitis, ventriculitis, with } \\
\text { perivascular gadolinium enhance- } \\
\text { ment }\end{array}$ & Albania & Male (65-year-old) \\
\hline
\end{tabular}




\section{DIAGNOSIS}

Diagnosis of NCC and especially of racemose form remains a great challenge and is based on a combination of clinical manifestations, neuroimaging and CSF findings, and reliable immune diagnostic tests. ${ }^{27}$ The revised diagnostic criteria published by Del Brutto et al. $^{28}$ in 2017 , offer a significant tool for the diagnosis of NCC with acceptable reliability and validity. For the clinicians important to remember is that definitive diagnosis can be made in those patients with two major neuroimaging criteria (cystic lesions without scolex, enhancing lesions, multilobulated cysts and calcifications) plus one clinical/exposure criteria (detection of anticysticercal antibodies or cysticercal antigens by well-standardized tests, systemic cysticercosis, evidence of a household Taenia carrier, suggestive clinical manifestations, and residency in endemic areas).

Although CT-Imaging is a reliable method to detect an hydrocephalus and calcified cysticerci, MRI of brain remains the best technique to distinguish cystic subarachnoid or intraventricular cysticerci with or without the coexistence of hydrocephalus, leptomeningeal enhancement or spinal involvement. ${ }^{29}$

The detection of specific antibodies or cysticercal antigens by immunodiagnostic tests is the next step in the diagnosis of NCC. The most reliable test for the detection of specific for T. Solium antigens in serum or CSF is the EITB assay using lectin-purified glycoprotein extracts. ${ }^{30}$ For patients with two or more viable or degenerating parasites in the central nervous system, or subarachnoid disease the sensitivity of EITB is $98 \%$ and the specificity $100 \%$. The sensitivity of EITB has been shown to be slightly lower in CSF than in serum (90\% vs. 100\%). The weaknesses of this method are the low sensitivity (50-60\%) in patients with only one intracranial cyst due to cysticercosis, the low sensitivity in patients with calcified cysticerci and the false positive test in asymptomatic population, especially in endemic areas. ${ }^{31}$ When EITB is not available the alternative method is the detection of anticysticercal antibodies by ELISA either in the CSF (sensitivity $89 \%$ and specificity 93\%) or in serum. The method is less reliable in serum rather than in CSF and also less reliable in patients with a few parenchymal cysts or in those with calcified cysticerci. ${ }^{32,33}$
CSF abnormalities are more frequently associated with the ventricular/subarachnoid form of the disease and with the presence of inflammation or multiple cysts. CSF abnormal findings include mononuclear pleocytosis, a mild to moderate increase in CSF protein concentration, elevated IgG-Index with positive oligoclonal bands and low concentrations of CSF glucose. Hypoglycorrhachia is associated with poorer prognosis. $^{29,34}$

\section{MANAGEMENT APPROACH}

There are numerous studies about the optimal management of the parenchymal NCC. Monotherapy with albendazole is recommended for patients with one or two cystic lesions and the combination of albendazole with praziquantel for those with multiple cysts. Patients, who present with seizures or headache, have a favorable response to antiparasitic therapy in combination with corticosteroid and a first-line antiepileptic drug is in the most cases necessary. ${ }^{35}$

In contrast to parenchymal disease, the therapeutic approach in patients with ventricular or subarachnoid NCC is different. In the ventricular disease consensus guidelines favoured endoscopic removal of cysts in the lateral and third ventricles with a flexible ventriculoscope and an individualized approach to cysticerci in the $4^{\text {th }}$ ventricle (the most favorable is the posterior approach).$^{36}$ High risk of bleeding is observed when the cysts are adhered to the ventricular wall. After successful removal of isolated intraventricular cysts antiparasitic or cortisosteroid therapy is no more needed. A preoperative antiparasitic therapy is also not recommended, because such a therapy could lead to disruption of parasite integrity with inflammatory response. A shunt surgery is suggested when inflammation or cyst's adherence to ventricular wall is observed and shunt insertion should be followed by the combination of antiparasitic with steroid therapy. A perioperative steroid therapy is also suggested when brain edema is observed $3^{37,29}$

Three steps are crucial for the management of subarachnoid NCC. ${ }^{29,30}$ Strongly recommended is the early begin of antiparasitic therapy, in most cases the combination of albendazole with praziquantel is preferable. 
Since all the complications in the subarachnoid form are the result of the inflammatory reaction to cysticidal antigens, anti-inflammatory therapy, initiated prior to antiparasitic drugs, is the next recommendation. Highdose corticosteroids, followed by a careful tapering, are suggested and as a steroid-sparing agent, (in order to avoid the steroid complications), the methotrexate is also recommended. ${ }^{9}$ For patients with hydrocephalus a shunt insertion in addition to medical therapy is also strongly suggested.$^{38}$ Since racemose NCC carries the worst prognosis among all forms of NCC with mortality ranging between $30 \%$ and $80 \%$ these patients should be under a close and long-term follow-up. Despite the fact that safe endpoints for therapy discontinuation are not well established, CSF cells \& glucose within normal range, absence of lesions in the follow-up MRI and negative cysticercal-antigen-tests may lead to end of treatment. ${ }^{39}$

\section{CONCLUSIONS}

Although racemose NCC is a rare disease, it should be considered in the differential diagnosis even in non-endemic countries due to increased travel and immigration across the endemic countries. Extraparenchymal cysticercosis could be mistaken for other common infectious of inflammatory diseases, including the primary CNS-angiitis. ${ }^{40}$ The present case highlights the importance of the timely diagnosis of racemose NCC in patients presenting with rapidly progressive dementia and gait instability. The swift initiation of neurosurgical and antibiotic treatments may be life-saving in this uncommon but devastating central nervous system disorder.

\section{Ethics Statement}

This case report is written according to CARE guidelines.

\section{Availability of Data and Material}

All data underlying the results are available as part of the article and no additional source data are required.

\section{Acknowledgments}

None.

\section{Sources of Funding}

None.

\section{Conflicts of Interest}

No potential conflicts of interest relevant to this article was reported.

\section{REFERENCES}

1. Relationship between epilepsy and tropical diseases. Commission on tropical diseases of the international league against epilepsy. Epilepsia. 1994;35:89-93.

2. Bustos JA, Coyle CM. Brain calcification because of neurocysticercosis: a vast field to be explored. Curr Opin Infect Dis. 2020;33:334-338.

3. García HH, Evans CA, Nash TE, Takayanagui OM, White AC Jr, Botero D, et al. Current consensus guidelines for treatment of neurocysticercosis. Clin Microbiol Rev. 2002;15:747756.

4. Venkat B, Aggarwal N, Makhaik S, Sood R. A comprehensive review of imaging findings in human cysticercosis. Jpn J Radiol. 2016;34:241-257.

5. Coyle CM. Neurocysticerosis: an individualized approach. Infect Dis Clin North Am. 2019;33:153-168.

6. Marcin Sierra M, Arroyo M, Cadena Torres M, Ramírez Cruz N, García Hernández F, Taboada D, et al. Extraparenchymal neurocysticercosis: demographic, clinicoradiological, and inflammatory features. PLoS Negl Trop Dis. 2017;11:e0005646.

7. Lescano AG, Garcia HH, Gilman RH, Gavidia CM, Tsang VC, Rodriguez S, et al. Taenia solium cysticercosis hotspots surrounding tapeworm carriers: clustering on human seroprevalence but not on seizures. PLoS Negl Trop Dis. 2009;3:e371.

8. Coyle CM, Mahanty S, Zunt JR, Wallin MT, Cantey PT, White Jr. AC, et al. Neurocysticercosis: neglected but not forgotten. PLoS Negl Trop Dis. 2012;6:9-11.

9. White AC Jr, Coyle CM, Rajshekhar V, Singh G, Hauser WA, Mohanty A, et al. Diagnosis and treatment of neurocysticercosis: 2017 clinical practice guidelines by the Infectious Diseases Society of America (IDSA) and the American Society of Tropical Medicine and Hygiene (ASTMH). Clin Infect Dis. 2018;66:e49-e75.

10. World Health Organization. Taeniasis and cysticercosis. [Internet]. 2021 May 17 [cited 2021 May 17] Available from 
http://www.who.int/taeniasis/en/

11. Bazan R, Hamamoto Filho PT, Luvizutto GJ, Nunes HR, Odashima NS, Dos Santos AC, et al. Clinical symptoms, imaging features and cyst distribution in the cerebrospinal fluid compartments in patients with extraparenchymal neurocysticercosis. PLoS Negl Trop Dis. 2016;10:e0005115.

12. Mahale RR, Mehta A, Rangasetty S. Extraparenchymal (racemose) neurocysticercosis and its multitude manifestations: a comprehensive review. J Clin Neurol. 2015;11:203-211.

13. Kimura-Hayama ET, Higuera JA, Corona-Cedillo R, Chávez-Macías L, Perochena A, Quiroz-Rojas LY, et al. Neurocysticercosis: radiologic-pathologic correlation. Radiographics. 2010;30:1705-1719.

14. Yerneni K, Karras C, Weiss HK, Horbinski CM, Bloch O. Intraventricular adult Taenia solium causing hydrocephalus: a case report. Surg Neurol Int. 2020;11:202.

15. Diehl Rodriquez R, Crestani DN, Dworzecki Soares JO, Franceshini PR, Petersen Alves R, Zimerman R, et al. Bruns' syndrome and racemose neurocysticercosis: a case report. Rev Soc Bras Med Trop. 2012;45:269-271.

16. Machado-Porto GCL, Lucato LT, Porto FH de G, de Souza EC, Nitrini R. Reversible dementia due to Neurocysticercosis: improvement of the racemose type with antihistamines. Dement Neuropsychol. 2015;9:85-90.

17. Kumar S, Thakur S, Jhobta A, Sood RG. Giant racemose neurocysticercosis with mass effect: unusual presentation. Ann Indian Acad Neurol. 2013;16:398-399.

18. Hamamoto Filho PT, Poliseli GB, Oliveira VA, Vital RB, Ferreira Lima MM, Bazan R, et al. Unusual painful trigeminal neuropathy caused by racemose neurocysticercosis. Pain Med. 2016;17:992-994.

19. Dutta D, Kumar M, Ghosh S, Mukhopadhyay S, Chowdhury S. Pituitary hormone deficiency due to racemose neurocysticercosis. Lancet Diabetes Endocrinol. 2013;1:e13.

20. Matalia J, Anaspure H, Kasturi N, Shetty BK. Chronic papilledema with vision loss as the presenting feature in racemose neurocysticercosis. Can J Ophthalmol. 2014;49:e26-e28.

21. Levy AS, Lillehei KO, Rubinstein D, Stears JC. Subarachnoid neurocysticercosis with occlusion of the major intracranial arteries: case report. Neurosurgery. 1995;36:183-188; discussion 188.

22. Arauz A, Ruiz-Navarro F, Silos H, Vargas-González JC, Arguelles-Morales N, Reyes M, et al. Concurrent asymptomatic inflammatory aneurysm and ischemic stroke due to cysticercal arteritis. Clin Neurol Neurosurg. 2013;115:2540-2542. 23. Alarcón F, Vanormelingen K, Moncayo J, Viñán I. Cerebral cysticercosis as a risk factor for stroke in young and middle-aged people. Stroke. 1992;23:1563-1565.

24. Marquez JM, Arauz A. Cerebrovascular complications of neurocysticercosis. Neurologist. 2012;18:17-22.

25. Hansberry DR, Agarwal N, Sharer LR, Goldstein IM. Minimally manipulative extraction of polycystic cervical neurocysticercosis. Eur Spine J. 2017;26(Suppl 1):63-68.

26. Yacoub HA, Goldstein I, El-Ghanem M, Sharer L, Souayah N. Spinal racemose cysticercosis: case report and review. Hosp Pract (1995). 2017;45:99-103.

27. Carpio A, Fleury A, Romo ML, Abraham R, Fandiño J, Durán JC, et al. New diagnostic criteria for neurocysticercosis: reliability and validity. Ann Neurol. 2016;80:434-442.

28. Del Brutto OH, Nash TE, White AC Jr, Rajshekhar V, Wilkins PP, Singh G, et al. Revised diagnostic criteria for neurocysticercosis. J Neurol Sci. 2017;372:202-210.

29. Nash TE, Garcia HH. Diagnosis and treatment of neurocysticercosis. Nat Rev Neurol. 2011;7:584-594.

30. Garcia HH, Nash TE, Del Brutto OH. Clinical symptoms, diagnosis, and treatment of neurocysticercosis. Lancet Neurol. 2014;13:1202-1215.

31. Garcia HH, O'Neal SE, Noh J, Handali S; Cysticercosis Working Group in Peru. Laboratory Diagnosis of Neurocysticercosis (Taenia solium). J Clin Microbiol. 2018;56:e0042418.

32. Odashima NS, Takayanagui OM, Figueiredo JF. Enzyme linked immunosorbent assay (ELISA) for the detection of IgG, IgM, IgE and IgA against cysticercus cellulosae in cerebrospinal fluid of patients with neurocysticercosis. Arq Neuropsiquiatr. 2002;60:400-405.

33. Michelet L, Fleury A, Sciutto E, Kendjo E, Fragoso G, Paris L, et al. Human neurocysticercosis: comparison of different diagnostic tests using cerebrospinal fluid. J Clin Microbiol. 2011;49:195-200.

34. Bazan R, Odashima NS, Luvizutto GJ, Hamamoto Filho PT, Zanini MA, Takayanagui OM. Analysis of cerebrospinal fluid in racemose form of neurocysticercosis. Arq Neuropsiquiatr. 2015;73:852-855.

35. Del Brutto OH, Roos KL, Coffey CS, García HH. Meta-analysis: cysticidal drugs for neurocysticercosis: albendazole and praziquantel. Ann Intern Med. 2006;145:43-51.

36. Proaño JV, Torres-Corzo J, Rodríguez-Della Vecchia R, Guizar-Sahagun G, Rangel-Castilla L. Intraventricular and subarachnoid basal cisterns neurocysticercosis: a comparative study between traditional treatment versus neuroendoscopic surgery. Childs Nerv Syst. 2009;25:1467-1475. 
Kollia et al. Racemose NCC and Neuroimaging Findings

37. Rajshekhar V. Surgical management of neurocysticercosis. Int J Surg. 2010;8:100-104.

38. Kelley R, Duong DH, Locke GE. Characteristics of ventricular shunt malfunctions among patients with neurocysticercosis. Neurosurgery. 2002;50:757-761; discussion 761-762.

39. Garcia HH, Parkhouse RM, Gilman RH, Montenegro T,
Bernal T, Martinez SM, et al. Serum antigen detection in the diagnosis, treatment, and follow-up of neurocysticercosis patients. Trans R Soc Trop Med Hyg. 2000;94:673-676.

40. Barinagarrementeria F, Cantu C. Frequency of cerebral arteritis in subarachnoid cysticercosis: an angiographic study. Stroke. 1998;29:123-125. 